\title{
KONTRIBUSI PENGARUH FAKTOR DAN VARIABEL YANG MEMENGARUHI CAPAIAN MUTU PELAKSANAAN PRESERVASI JEMBATAN
}

\author{
Novi Ari Nugroho \\ MSTT FT UGM \\ Jln. Grafika 2, Kampus UGM \\ Yogyakarta 55281 \\ novi.ari.nugroho@ugm.ac.id \\ Iman Satyarno \\ MSTT FT UGM \\ Jln. Grafika 2, Kampus UGM \\ Yogyakarta 55281 \\ imansatyarno@ugm.ac.id
}

\author{
Agus Taufik Mulyono \\ MSTT FT UGM \\ Jln. Grafika 2, Kampus UGM \\ Yogyakarta 55281 \\ agus.taufik.mulyono@ugm.ac.id \\ Latif Budi Suparma \\ MSTT FT UGM \\ Jln. Grafika 2, Kampus UGM \\ Yogyakarta 55281 \\ lbsuparma@ugm.ac.id
}

\begin{abstract}
Bridges are an important part of a road network system, so they need to be kept functioning properly. Bridge preservation is one of the important and fundamental types of handling to maintain the condition of the bridge in good condition and restore the condition of the bridge to its original capacity so that it can serve effectively. The purpose of this study is to identify the contribution of the influence of factors and variables that affect the quality of the implementation of bridge preservation. Data analysis was based on the results of a survey of respondents who came from service users, service providers and the public who had been involved in implementing bridge preservation. The analysis was conducted using the Structural Equation Modeling method. The results showed that the implementation of bridge preservation factors and variables that influence the implementation of bridge preservation influence on the achievement of the quality of the bridge preservation of $60.6 \%$. The contribution of the influence of the factors that affect the quality of the implementation of the bridge preservation is the human resource factor contributing to the effect of $89.4 \%$, a material factor of $81.8 \%$, a method factor of $80.7 \%$, a tool factor of $68.7 \%$, a factor financial contribution of $54.0 \%$, and environmental factors contributed an influence of $53.1 \%$. To realize good quality achievements, the parties involved in implementing bridge preservation must pay attention to 6 factors and 33 important variables to be able to support these quality achievements.
\end{abstract}

Keywords: bridge preservation; Structural Equation Modelling; influence contribution; quality achievement.

\begin{abstract}
Abstrak
Jembatan merupakan bagian yang penting dalam suatu sistem jaringan jalan, sehingga perlu dijaga agar tetap berfungsi dengan baik. Preservasi jembatan merupakan salah satu jenis penanganan yang penting dan mendasar untuk mempertahankan kondisi jembatan dalam kondisi baik dan mengembalikan kondisi jembatan sesuai kapasitas semula sehingga dapat melayani dengan efektif. Tujuan penelitian ini adalah mengidentifikasi kontribusi pengaruh dari faktor dan variabel yang memengaruhi capaian mutu pelaksanaan preservasi jembatan. Data analisis berdasarkan hasil survei terhadap responden yang berasal dari pengguna jasa, penyedia jasa dan publik yang pernah terlibat dalam pelaksanaan preservasi jembatan. Analisis dilakukan dengan metode Structural Equation Modelling. Hasil penelitian menunjukkan bahwa pada pelaksanaan preservasi jembatan faktor dan variabel yang memengaruhi pelaksanaan preservasi jembatan memberikan pengaruh terhadap capaian mutu pelaksanaan preservasi jembatan sebesar $60,6 \%$. Kontribusi pengaruh dari faktor-faktor yang memengaruhi capaian mutu pelaksanaan preservasi jembatan adalah faktor sumber daya manusia memberikan kontribusi pengaruh sebesar $89,4 \%$, faktor material sebesar $81,8 \%$, faktor metode sebesar $80,7 \%$, faktor alat sebesar $68,7 \%$, faktor keuangan sebesar 54,0\%, dan faktor lingkungan memberikan konstribusi pengaruh sebesar 53,1\%. Untuk mewujudkan capaian mutu yang baik, pihak-pihak yang terlibat dalam pelaksanaan preservasi jembatan harus memerhatikan 6 faktor dan 33 variabel penting untuk dapat mendukung capaian mutu tersebut.
\end{abstract}

Kata-kata kunci: preservasi jembatan; Structural Equation Modelling; kontribusi pengaruh; capaian mutu. 


\section{PENDAHULUAN}

Jembatan adalah struktur yang melintasi sungai, saluran, lembah, dan selat, atau laut, jalan raya, dan jalan kereta api. Maka jembatan merupakan bagian yang penting dalam suatu sistem jaringan jalan, sehingga perlu dijaga agar tetap berfungsi dengan baik. Kerusakan atau keruntuhan jembatan akan mengurangi atau menahan lalu lintas, yang berarti mengganggu kelancaran transportasi orang dan barang (Hariman, 2007). Dengan demikian infrastruktur jembatan harus selalu dalam keadaan baik dan terpelihara sampai dengan umur layan jembatan.

Preservasi jembatan merupakan salah satu jenis penanganan yang penting dan mendasar untuk mempertahankan kondisi jembatan dalam kondisi baik dan mengembalikan kondisi jembatan sesuai kapasitas semula sehingga dapat melayani dengan efektif. Pencapaian mutu hasil pekerjaan pemeliharaan jembatan selain dipengaruhi faktor engineering juga dipengaruhi oleh faktor-faktor yang lain, seperti sumber daya dan faktor lingkungan. Salah satu contoh kegagalan capaian mutu pelaksanaan preservasi jembatan dapat dilihat pada peristiwa runtuhnya Jembatan Kutai Kertanegara pada saat pelaksanaan preservasi jembatan.

Tujuan penelitian ini adalah untuk menganalisis kontribusi pengaruh tiap faktor yang memengaruhi kualitas mutu pelaksanaan preservasi jembatan (Sumber Daya Manusia atau SDM, keuangan, metode kerja, peralatan, material, dan lingkungan). Dengan mengetahui kontribusi pengaruh dari faktor dan indikator yang memengaruhi pelaksanaan preservasi jembatan diharapkan dapat menjadi pertimbangan yang penting dalam pelaksanaan preservasi jembatan sehingga dapat terlaksana secara efektif dan efisien serta dapat mewujudkan capaian mutu hasil pekerjaan yang baik.

Preservasi merupakan upaya mempertahankan suatu struktur jembatan dari penurunan kualitas atau kerusakan, melalui kegiatan pemeliharaan rutin, berkala, rehabilitasi (perbaikan dan perkuatan) untuk mempertahankan dan mengembalikan fungsi jembatan (Pusjatan, 2010). Dalam pelaksanaanya, kegiatan preservasi jembatan memerlukan sumber daya yang saling terkait agar pelaksanaan preservasi dapat berjalan secara maksimal. Pengelolaan yang baik terhadap sumber daya dapat menghasilkan penghematan biaya proyek yang dikeluarkan. Kirschenman (1987) menyatakan bahwa anggaran untuk pengelolaan sumber daya dapat dianggap sebagai investasi dalam suatu proyek konstruksi. Partogi dan Mulyono (2015) menyatakan bahwa solusi penanganan untuk mengatasi permasalahan kinerja kontraktor tersebut dapat ditempuh dengan perbaikan tata kelola SDM, tata laksana operasional, dan tata kelola organisasi. Laksono (2007) menyatakan bahwa terdapat beberapa faktor sumber daya yang memengaruhi produktivitas dan kualitas suatu proyek konstruksi, yaitu: (a) tenaga kerja; (b) peralatan; (c) bahan; (d) dana yang tersedia; (e) kondisi lingkungan proyek; dan (f) metode kerja.

\section{METODE PENELITIAN}

Instrumen pengumpulan data yang digunakan dalam penelitian ini adalah kuesioner. Kuesioner dalam penelitian ini memuat pertanyaan yang bertujuan untuk mengetahui tingkat 
kepentingan tiap faktor yang dapat memengaruhi terjadinya penyimpangan mutu selama pelaksanaan preservasi jembatan. Skala pengukuran yang digunakan dalam penelitian ini adalah skala Likert. Penentuan skala pengukuran perlu dilakukan dalam penelitian karena untuk mengetahui respon responden dalam menjawab pertanyaan yang diajukan dalam sebuah kuesioner. Pemilihan skala Likert dalam penelitian ini bertujuan untuk mengukur tanggapan responden tentang obyek sosial yang memiliki banyak pilihan respon. Dalam penelitian ini responden diminta untuk memberikan penilaian terhadap kriteria dan subkriteria kinerja kontraktor dan pengelola swakelola terhadap kepentingan capaian mutu pelaksanaan preservasi jembatan, dalam hal nilai kepengaruhan atau tingkat kepentinganya. Penilaian menggunakan skala Likert untuk tingkat kepentingan, yaitu (1) artinya berpengaruh sangat besar; (2) artinya berpengaruh besar; (3) artinya berpengaruh kecil; dan (4) artinya berpengaruh sangat kecil.

Dalam penelitian ini subyek penelitian berasal dari pihak-pihak yang pernah terlibat dalam kegiatan preservasi jembatan di Lingkungan Kementerian Pekerjaan Umum dan Perumahan Rakyat. Pihak-pihak tersebut berasal dari unsur pengguna jasa, penyedia jasa, dan publik.

Tabel 1 Faktor dan Variabel Penelitian

\begin{tabular}{|c|c|}
\hline Kode & Faktor dan Variabel \\
\hline A & Faktor sumber daya manusia (tenaga kerja) pekerjaan preservasi jembatan \\
\hline A1 & Keterampilan tenaga kerja pekerjaan preservasi jembatan \\
\hline A2 & Kepatuhan tenaga kerja terhadap penerapan standar mutu preservasi jembatan \\
\hline A3 & Pengalaman tenaga kerja dalam bidang pekerjaan konstruksi jembatan \\
\hline A4 & Ketersediaan tenaga kerja pada saat pelaksanaan preservasi jembatan \\
\hline A5 & Kepatuhan tenaga kerja terhadap ketentuan K3 pada pelaksanaan preservasi jembatan \\
\hline A6 & Kesesuaian penempatan tenaga kerja sesuai keterampilan \\
\hline A7 & Koordinasi antartenaga kerja di lokasi pekerjaan pada saat pelaksanaan preservasi jembatan \\
\hline $\mathrm{B}$ & Faktor bahan (material) pekerjaan preservasi jembatan \\
\hline B1 & Ketepatan waktu pengiriman material ke lokasi pekerjaan preservasi jembatan \\
\hline B2 & Ketepatan jumlah material yang disediakan untuk preservasi jembatan \\
\hline B3 & Kondisi penyimpanan material di lokasi base camp proyek \\
\hline B4 & Ketepatan mutu material preservasi jembatan \\
\hline B5 & Ketersediaan sumber material untuk pekerjaan preservasi jembatan \\
\hline $\mathrm{C}$ & Faktor peralatan pekerjaan preservasi jembatan \\
\hline $\mathrm{C} 1$ & Keterampilan operator peralatan berat preservasi jembatan \\
\hline $\mathrm{C} 2$ & Jumlah dan jenis peralatan berat preservasi jembatan \\
\hline $\mathrm{C} 3$ & Kelaikan fungsi alat berat preservasi jembatan \\
\hline $\mathrm{C} 4$ & Kondisi peralatan berat pada saat pelaksanaan pekerjaan preservasi jembatan \\
\hline $\mathrm{C} 5$ & Ketepatan waktu pengiriman peralatan berat pelaksanaan preservasi jembatan \\
\hline C6 & Ketersediaan suku cadang alat atau alat berat preservasi jembatan \\
\hline $\mathrm{D}$ & Faktor pelaksanaan dan metode kerja pekerjaan preservasi jembatan \\
\hline D1 & Penerapan standar mutu preservasi jembatan \\
\hline D2 & Ketepatan jenis penanganan perbaikan terhadap kerusakan yang terjadi \\
\hline D3 & Pembuatan laporan kemajuan kegiatan preservasi jembatan \\
\hline D4 & Kepastian waktu tanggap dan penyelesaian perbaikan kerusakan \\
\hline D5 & Peranan Pejabat Pembuat Komitmen terhadap monitoring dan pengendalian \\
\hline $\mathrm{E}$ & Faktor keuangan (financing) saat pelaksanaan pekerjaan preservasi jembatan \\
\hline E1 & Tercapainya target penyerapan keuangan preservasi jembatan \\
\hline $\mathrm{E} 2$ & Ketepatan waktu pembayaran hasil kerja oleh PPK kepada kontraktor dan pengelola swakelola \\
\hline E3 & $\begin{array}{l}\text { Kesesuaian harga penawaran preservasi dengan biaya preservasi selama pelaksanaan preser- } \\
\text { vasi jembatan }\end{array}$ \\
\hline
\end{tabular}


Tabel 1 Faktor dan Variabel Penelitian (Lanjutan)

\begin{tabular}{cl}
\hline Kode & \multicolumn{1}{c}{ Faktor dan Variabel } \\
\hline E4 & Fluktuasi harga material bangunan jembatan di pasar \\
E5 & $\begin{array}{l}\text { Ketepatan waktu pembayaran kepada subkontraktor dan tenaga kerja oleh kontraktor dan pe- } \\
\text { ngelola swakelola }\end{array}$ \\
F & Faktor lingkungan lokasi pekerjaan preservasi jembatan \\
F1 & Antisipasi terhadap kondisi cuaca (hujan) selama pelaksanaan preservasi jembatan \\
F2 & Antisipasi terhadap gangguan sosial ekonomi masyarakat setempat selama pelaksanaan preser- \\
& vasi jembatan \\
F3 & Ketersediaan sarana dan prasarana pendukung pada saat preservasi jembatan \\
F4 & Kondisi volume lalu lintas saat pelaksanaan preservasi jembatan \\
F5 & $\begin{array}{l}\text { Pengaruh force major (banjir, longsor, gempa, dan bencana lainnya) di lokasi preservasi jem- } \\
\text { batan }\end{array}$ \\
G & Indikator capaian mutu \\
G1 & Nilai kondisi jembatan (NK) = 1 \\
G2 & Bangunan bawah tidak boleh ada retakan atau pecah pada beton dan pasangan batu, serta bersih \\
& dari kotoran \\
G3 & Bangunan atas tidak ada karat atau pengelupasan cat pada struktur baja serta sambungan tidak \\
G4 & longgar dan aus \\
G5 & Bantai jembatan dan drainase harus bersih dari kotoran atau tumbuhan liar \\
& sakan
\end{tabular}

Analisis data dilakukan dengan menggunakan metode Structural Equation Model (SEM) dan bantuan software AMOS. SEM digunakan untuk mendefinisikan hubungan antarfaktor yang akan diteliti. Ghozali (2017) mengungkapkan, Structural Equation Modeling (SEM) pada dasarnya terdiri atas 2 bagian, yaitu: (1) bagian pengukuran yang menghubungkan observed variable dengan variabel laten melalui confirmatory factor analysis, dan (2) bagian struktur yang menghubungkan antarvariabel lewat persamaan regresi simultan. Dalam proses analisis SEM, hubungan-hubungan antarvariabel dinyatakan dalam suatu model, kemudian model tersebut diestimasi dan keluarannya dievaluasi. Model dievaluasi pada kriteria kecocokan model atau Goodness of Fit (GOF) dan hubungan-hubungan variabel dievaluasi pada kriteria nilai bobot atau koefisien regresi. Model hubungan dapat diterima apabila memenuhi persyaratan nilai batas penerimaan kriteria GOF model, yaitu

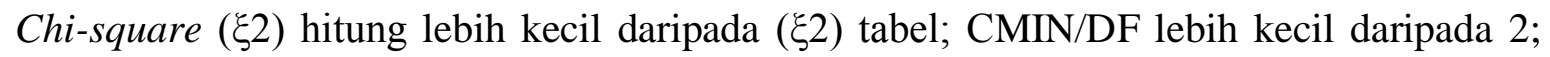
probabilitas (p) lebih besar daripada 0,050; GFI lebih besar daripada 0,900; AGFI lebih besar daripada 0,900; TLI lebih besar daripada 0,900; dan RMSEA lebih kecil daripada 0,080. Nilai bobot atau koefisien regresi untuk menyatakan indikator layak menjadi pengukur konstruk adalah nilai bobot yang lebih besar daripada 0,500 .

\section{HASIL PENELITIAN DAN PEMBAHASAN}

Responden yang mengisi dan mengembalikan kuesioner sebanyak 130 responden. Responden terdistribusi merata mewakili pihak pengguna jasa, penyedia jasa dan publik. Instansi responden mewakili peran-peran yang langsung berkecimpung dengan dinamika pekerjaan konstruksi terutama bidang jembatan. Usia responden sebagian besar merupakan usia produktif kerja, yaitu antara 31 tahun sampai dengan 50 tahun, sehingga dapat membe- 
rikan jawaban sesuai dengan keadaan sebenarnya di lapangan berdasarkan pengalaman dan kinerja yang dimiliki. Sebagian besar responden memiliki tingkat pendidikan Sarjana (S1) dan Magister (S2). Dengan latar belakang pendidikan tersebut diharapkan responden dapat memberikan penilaian dan jawaban yang tepat sehingga dapat menggambarkan kondisi aktual yang terjadi di lapangan. Sebagian besar responden memiliki pengalaman kerja antara 11 tahun hingga 30 tahun, sehingga diharapkan keseluruhan reponden dapat memberikan penilaian dan jawaban yang tepat sesuai dengan kondisi aktual di lapangan. Responden sebagian besar telah memiliki sertifikat kompetensi di bidang jembatan, sehingga diharapkan dapat memberikan penilaian dan jawaban yang baik sesuai dengan kompetensi yang dimiliki oleh responden.

Hasil uji validitas data kuesioner menunjukkan hasil yang valid karena keseluruhan variabel pertanyaan menghasilkan nilai $r$ hitung lebih besar dari nilai $r$ tabel yang telah ditetapkan, yaitu 0.361. Dengan demikian dapat disimpulkan bahwa semua variabel pertanyaan dapat digunakan untuk mengukur tingkat kepentingan, yang dalam hal ini adalah capaian mutu tiap faktor yang memengaruhi kualitas mutu pelaksanaan preservasi jembatan. Hasil uji reliabilitas data kuesioner menunjukkan hasil yang realibel, karena keseluruhan faktor menghasilkan nilai cronbach's alpha yang lebih besar daripada nilai yang telah ditetapkan, yaitu 0,60 .

Tabel 2 Hasil Uji Goodness of Fit CFA Hubungan Variabel Konstruk Faktor Awal

\begin{tabular}{cccc}
\hline $\begin{array}{c}\text { Parameter } \\
\text { Goodness of Fit }\end{array}$ & Kriteria & Hasil Uji & Evaluasi \\
\hline Chi-square & Diharapkan kecil & 1351,78 & Tidak fit \\
CMIN/DF & $<2$ & 2,099 & Tidak fit \\
Probabilitas & $\geq 0,05$ & 0,000 & Tidak fit \\
GFI & $\geq 0,90$ & 0,660 & Tidak fit \\
AGFI & $\geq 0,90$ & 0,609 & Tidak fit \\
TLI & $\geq 0,90$ & 0,731 & Tidak fit \\
RMSEA & $\leq 0,08$ & 0,092 & Tidak fit \\
\hline
\end{tabular}

Setelah data lolos uji validitas dan reabilitas dilanjutkan dengan analisis dengan menggunakan metode SEM. Metode SEM digunakan karena memiliki kemampuan untuk mengukur pengaruh hubungan antar variabel sebagai sebuah unit. Tahapan yang dilaksanakan pada proses analisis data ini adalah: (1) menyusun model berdasar teori dengan menggambarkannya dalam bentuk diagram jalur dan persamaan matematis, (2) melakukan analisis konfirmatori faktor untuk mengidentifikasi hubungan indikator terhadap konstruk dan analisis regresi berganda atau multiple regression analysis untuk hubungan antarkonstruk, dan (3) menganalisis model komposit. Hasil analisis konfirmatori awal, seperti yang terdapat pada Gambar 1, masih menunjukkan bahwa semua nilai parameter belum masuk kriteria yang terdapat pada Tabel 2, sehingga dapat disimpulkan bahwa model belum fit, dan tidak terdapat nilai probabilitas $\mathrm{p}$ lebih besar daripada 0,05 serta tidak ada nilai indikator konstruk eksogen yang memiliki loading factor lebih besar daripada 0,50 pada modifikasi model tersebut. Tahap selanjutnya, untuk mengatasi masalah tersebut, adalah melakukan analisis konfirmatori faktor setiap faktor eksogen untuk mendapatkan indikator- 
indikator yang memengaruhi konstruk dan nilai factor score weight untuk melakukan proses penye-derhanaan model atau komposit.

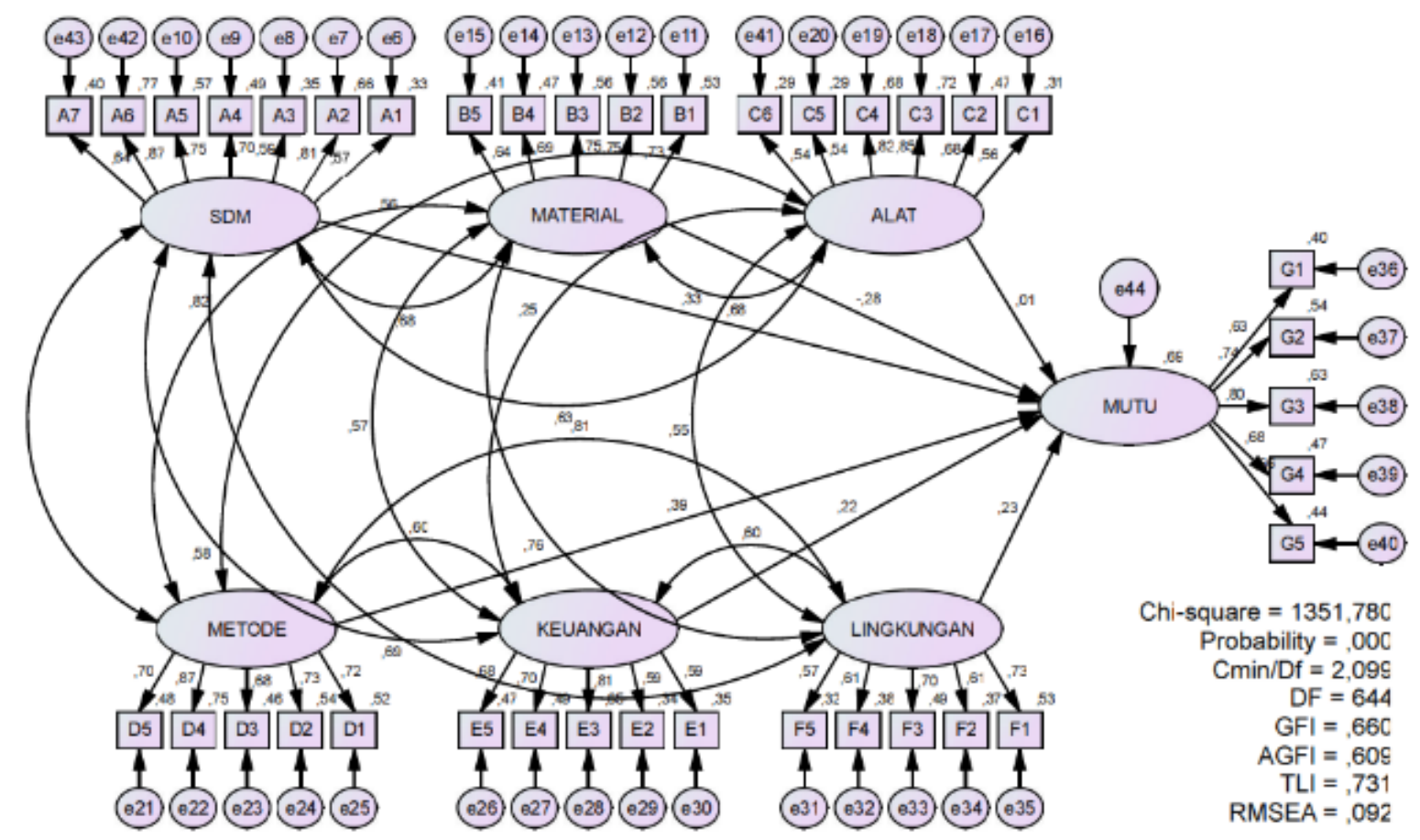

Gambar 1 Model Utuh Awal Hubungan Antarvariabel Konstruk

Tabel 3 Rekapitulasi Nilai FSW dari Hasil Analisis CFA Indikator Faktor Eksogen

\begin{tabular}{cc}
\hline Variabel & FSW \\
\hline SDM & \\
A1 & 0,014 \\
A2 & 0,082 \\
A3 & 0,059 \\
A4 & 0,107 \\
A5 & 0,058 \\
A6 & 0,253 \\
A7 & 0,068 \\
Material & \\
B1 & 0,100 \\
B2 & 0,298 \\
B3 & 0,099 \\
B4 & 0,150 \\
B5 & 0,113 \\
\hline
\end{tabular}

\begin{tabular}{cc}
\hline Variabel & FSW \\
\hline Alat & \\
C1 & 0,161 \\
C2 & 0,168 \\
C3 & 0,136 \\
C4 & 0,144 \\
C5 & 0,029 \\
C6 & 0,108 \\
Metode & \\
D1 & 0,250 \\
D2 & $-0,004$ \\
D3 & $-0,003$ \\
D4 & 0,551 \\
D5 & $-0,004$ \\
\hline
\end{tabular}

\begin{tabular}{cc}
\hline Variabel & FSW \\
\hline Keuangan & \\
E1 & 0,040 \\
E2 & 0,051 \\
E3 & 0,193 \\
E4 & 0,135 \\
E5 & 0,086 \\
Lingkungan & \\
F1 & 0,369 \\
F2 & 0,125 \\
F3 & 0,192 \\
F4 & 0,164 \\
F5 & 0,177 \\
\hline
\end{tabular}

Indikator-indikator hasil CFA konstruk faktor eksogen selanjutnya digunakan untuk menyusun model utuh final hubungan variabel faktor yang memengaruhi capaian mutu pelaksanaan preservasi jembatan. Model tersebut ditujukan untuk mengidentifikasi kekuatan hubungan komponen-komponen dalam faktor yang memengaruhi capaian mutu pelaksanaan preservasi jembatan dan mengidentifikasi besar pengaruh faktor tersebut terhadap capaian mutu pelaksanaan preservasi jembatan. Model utuh final dapat dilihat pada Gambar 2. 
Tabel 4 Rekapitulasi Nilai SRW dari Hasil Analisis CFA Indikator Faktor Eksogen

\begin{tabular}{|c|c|c|c|c|c|}
\hline Variabel & SRW & Variabel & SRW & Variabel & SRW \\
\hline SDM & & Alat & & Keuangan & \\
\hline A1 & 0,535 & $\mathrm{C} 1$ & 0,642 & $\mathrm{E} 1$ & 0,510 \\
\hline $\mathrm{A} 2$ & 0,778 & $\mathrm{C} 2$ & 0,749 & $\mathrm{E} 2$ & 0,554 \\
\hline A3 & 0,573 & C3 & 0,765 & E3 & 0,807 \\
\hline A4 & 0,715 & $\mathrm{C} 4$ & 0,757 & $\mathrm{E} 4$ & 0,742 \\
\hline A5 & 0,731 & $\mathrm{C} 5$ & 0,526 & E5 & 0,678 \\
\hline A6 & 0,888 & C6 & 0,564 & Lingkungan & \\
\hline A7 & 0,612 & Metode & & $\mathrm{F} 1$ & 0,814 \\
\hline Material & & D1 & 0,635 & $\mathrm{~F} 2$ & 0,542 \\
\hline B1 & 0,661 & D2 & 0,790 & F3 & 0,605 \\
\hline B2 & 0,830 & D3 & 0,736 & F4 & 0,621 \\
\hline B3 & 0,682 & D4 & 0,896 & F5 & 0,649 \\
\hline B4 & 0,722 & D5 & 0,579 & & \\
\hline B5 & 0,603 & & & & \\
\hline
\end{tabular}

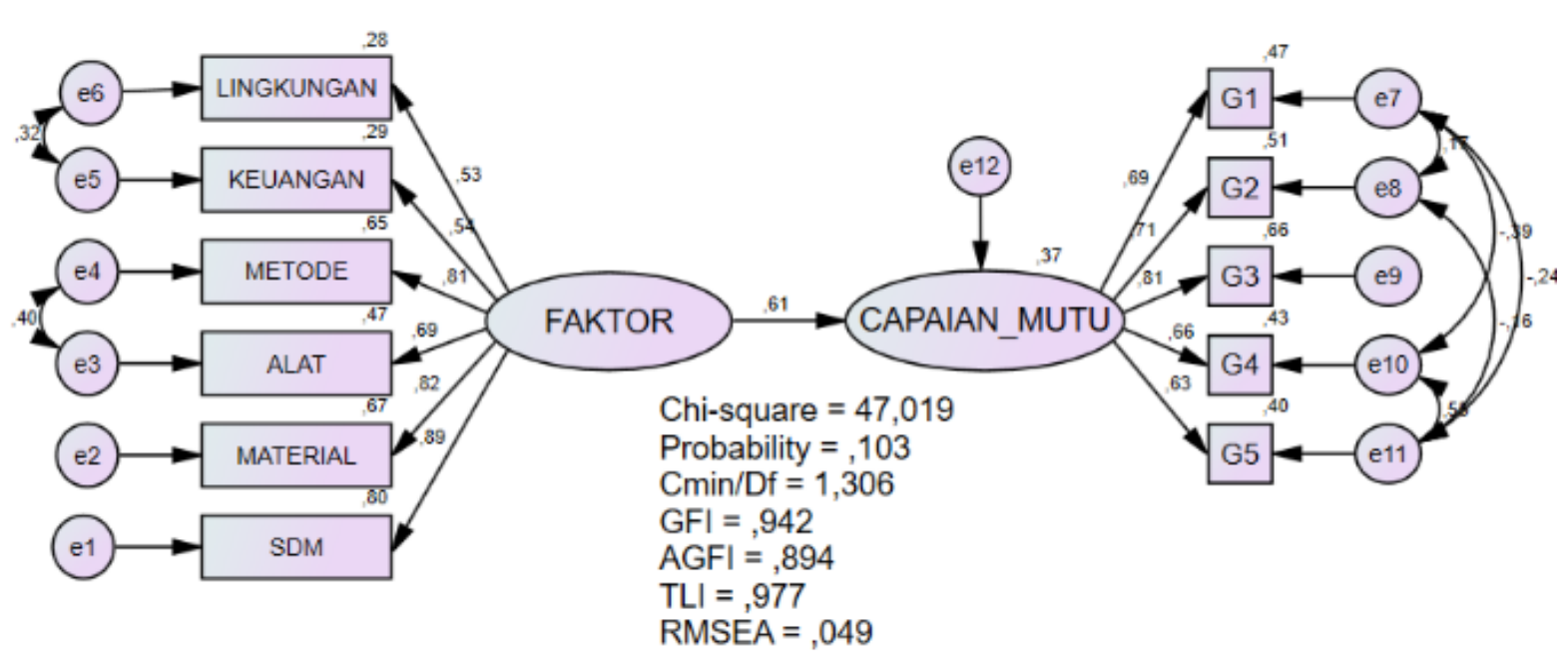

Gambar 2 Model Utuh Final Hubungan Variabel Faktor yang Memengaruhi Capaian Mutu Pelaksanaan Preservasi Jembatan

Hasil analisis model SEM seperti yang disajikan pada Gambar 2 terhadap berbagai kriteria Goodness of Fit didapatkan nilai masing-masing parameter: (a) Chi-square bernilai 47,019; (b) CMIN/DF bernilai 1,306; (c) probabilitas bernilai 0,103; (d) GFI bernilai 0,942; (e) AGFI bernilai 0,894; (f) TLI bernilai 0,977; dan (g) RMSEA bernilai 0,049. Nilai-nilai parameter hasil analisis ini menunjukkan bahwa model fit.

Hasil analisis model utuh final, seperti yang disampaikan pada Gambar 2, menunjukkan bahwa konstruk faktor mempunyai nilai pengaruh sebesar 0,606 (60,6\%) terhadap konstruk capaian mutu. Bobot kontribusi masing-masing faktor yang memengaruhi capaian mutu pelaksanaan preservasi jembatan berturut-turut, dari yang terbesar, adalah sebagai berikut: (1) faktor SDM yang mempunyai bobot sebesar 0,894 (89,4\%); (2) faktor material yang mempunyai bobot sebesar $0,818(81,8 \%)$; (3) faktor metode yang mempunyai bobot 
sebesar 0,807 (80,7\%); (4) faktor alat yang mempunyai bobot sebesar 0,687 (68,7\%); (5) faktor keuangan yang mempunyai bobot sebesar 0,540 (54,0\%); dan (6) faktor lingkungan yang mempunyai bobot sebesar 0,531 (53,1\%). Bobot kontribusi masing-masing indikator kinerja dari capaian mutu pelaksanaan preservasi jembatan berturut-turut dari yang terbesar adalah sebagai berikut: (1) bangunan atas tidak ada karat atau pengelupasan cat pada struktur baja serta sambungan tidak longgar dan aus (G3) yang mempunyai bobot sebesar 0,814 (81,4\%); (2) bangunan bawah tidak boleh ada retakan atau pecah pada beton dan pasangan batu, serta bersih dari kotoran (G2) yang mempunyai bobot sebesar 0,715 (71,5\%); (3) nilai kondisi jembatan $(\mathrm{NK})=1$ (G1) yang mempunyai bobot sebesar 0,689 (68,9\%); (4) lantai jembatan dan drainase harus bersih dari kotoran atau tumbuhan liar (G4) yang mempunyai bobot sebesar 0,658 (65,8\%); dan (5) bangunan pelengkap harus bersih dari kotoran, terpasang dengan benar dan tidak ada kerusakan (G5) yang mempunyai bobot sebesar 0,634 $(63,4 \%)$.

Hasil penelitian ini menunjukkan bahwa faktor-faktor pengaruh, yang terdiri atas komponen SDM, material, alat, metode, keuangan, dan lingkungan, berperan dalam pencapaian mutu pelaksanaan preservasi jembatan. Enam variabel komponen faktor pengaruh tersebut memiliki hubungan yang signifikan dalam pengaruh capaian mutu pelaksanaan. Oleh karena itu, dalam pelaksanaan preservasi jembatan pengelolaan terhadap sumber daya dan proses harus dilaksanakan dengan memerhatikan enam komponen faktor tersebut untuk memaksimalkan kontribusi terhadap capaian mutu. Pengelolaan komponen faktor pengaruh tersebut dapat memberikan kontribusi secara maksimal apabila dalam pelaksanaan preservasi jembatan memenuhi 33 variabel penting yang terseleksi, seperti yang disampaikan pada Tabel 1.

Komponen sumber daya manusia (SDM) memiliki pengaruh yang dominan pada faktor pengaruh pelaksanaan pekerjaan preservasi jembatan dalam rangka pencapain mutu hasil pekerjaan. Dalam pelaksanaan preservasi jembatan kinerja yang baik akan memengaruhi capaian mutu yang baik dari hasil pelaksanaan. Kinerja dinilai dari apa yang telah dicapai dan dihasilkan oleh individu dalam melaksanakan tugas dan kinerjanya. Individu di sini adalah sumber daya manusia (pekerja), pada umumnya kinerja dari pekerja yang bagus akan menghasilkan pelaksanaan proyek yang bagus pula.

Variabel kesesuaian penempatan tenaga kerja sesuai keterampilan (A6) mempunyai koefisien jalur yang paling besar dalam indikator SDM seperti yang disampaikan pada Tabel 4. Keterampilan adalah kemampuan dan penguasan teknis operasional mengenai bidang tertentu yang bersifat kekaryaan. Oleh karena itu, secara logis penempatan tenaga kerja sesuai dengan keterampilan yang dimiliki sangat berpengaruh dalam pencapaian mutu karena jika pekerja tidak ditempatkan sesuai dengan keterampilan yang dimiliki maka hasil dari pekerjaan tersebut tidak akan berhasil dan tidak dapat mencapai hasil atau mutu yang baik.

Komponen lingkungan secara empiris memiliki peran vital dalam pelaksanaan preservasi jembatan. Lingkungan menggambarkan karakteristik dari alam dan entitas penyusunnya serta interaksi, dinamika dan fenomena yang terjadi di antaranya. Pada umumnya kegiatan manusia harus menyesuaikan diri terhadap unsur lingkungan termasuk dalam 
pelaksanaan preservasi jembatan dapat tercapai mutu yang baik dengan memerhatikan kondisi lingkungan di sekitar lokasi pekerjaan.

Variabel antisipasi terhadap kondisi cuaca (hujan) selama pelaksanaan preservasi jembatan (F1) memiliki kontribusi pengaruh yang paling besar terhadap komponen lingkungan seperti yang disampaikan pada Tabel 4. Hal ini sangat logis karena dalam pelaksanaan pekerjaan jika tidak mengantisipasi kondisi cuaca (hujan) maka dapat menghambat dan bahkan bisa menghentikan pelaksanaan pekerjaan. Oleh karenanya, antisipasi dalam pelaksanaan pekerjaan terhadap faktor cuaca (hujan) sangat berpengaruh dalam pencapain mutu hasil pekerjaan.

Mutu hasil pekerjaan dalam pelaksanaan preservasi jembatan dapat terwujud dengan dukungan pelaksanaan yang cermat dengan memerhatikan optimalisasi dari faktor pengaruh dan indikatornya dalam capaian mutu pelaksanaan preservasi jembatan. Kinerja dari hasil pekerjaan harus dapat diukur untuk mengevaluasi keberhasilan pelaksanaan pekerjaan yang dicerminkan dalam capaian mutu hasil pekerjaan tersebut.

Bangunan atas tidak ada karat atau pengelupasan cat pada struktur baja serta sambungan tidak longgar dan aus menjadi indikator yang paling kuat dalam mengukur pencapaian mutu hasil pekerjaan. Kondisi fisik yang langsung terlihat oleh indera adalah ukuran yang mudah untuk menilai keadaaan suatu hal. Bangunan atas dalam kondisi baik apabila tidak terdapat karat atau penglupasan cat serta sambungan tidak mengalami longgar dan aus. Selain bangunan atas, bangunan bawah tidak boleh ada retakan atau pecah pada beton dan pasangan batu, serta bersih dari kotoran juga bisa menjadi indikasi visual dengan kondisi baik dalam struktur jembatan. Hal tersebut menunjukkan bahwa struktur bangunan bawah dapat memikul beban dari bangunan atas dan beban hidup di atasnya sesuai dengan desain yang direncanakan.

Kinerja jembatan dinilai secara keseluruhan dengan pemeriksaan jembatan yang dilakukan. Nilai kondisi jembatan sangat memegang peran penting untuk tindak lanjut kedepan dalam penanganan struktur jembatan. Hasil penilaian kondisi jembatan diperlukan dalam menentukan perlu tidaknya dilakukan pemeriksaan yang lebih detail ataupun jenis pemeliharaan yang akan dilakukan.

Lantai jembatan dan drainase harus bersih dari kotoran atau tumbuhan liar merupakan salah satu indikator penting dalam capaian mutu pelaksanaan, kebersihan dari kotoran dan tumbuhan liar dapat menjaga struktur lantai jembatan dari pengaruh karbonasi sehingga struktur lantai jembatan dapat melayani dengan baik sesuai dengan masa layan yang direncanakan.

Indikator bangunan pelengkap harus bersih dari kotoran, terpasang dengan benar dan tidak ada kerusakan mempunyai bobot kontribusi terendah di antara 5 indikator capaian mutu lainnya karena bangunan pelengkap bukan merupakan kesatuan dalam struktur utama jembatan. Walaupun bukan merupakan kesatuan dalam struktur utama jembatan, bangunan pelengkap juga memegang peranan penting dalam memberikan tanda ataupun peringatan bagi pengguna jembatan sehingga harus bersih dari kotoran dan harus terpasang dengan benar sesuai standar pemasangan yang berlaku. 


\section{KESIMPULAN}

Strategi pengelolaan dari faktor-faktor yang memengaruhi capaian mutu pelaksanaan preservasi jembatan memiliki pengaruh yang siginifikan terhadap tingkat capaian mutu yang diperoleh. Proses pelaksanaan preservasi jembatan harus memerhatikan 33 variabel dari 6 komponen faktor pengaruh, yaitu SDM, material, metode, alat, keuangan dan lingkungan, untuk dapat mendukung perolehan capaian mutu yang baik. Faktor SDM memberikan kontribusi pengaruh paling besar terhadap faktor yang memengaruhi capaian mutu pelaksanaan preservasi jembatan, berturut-turut dilanjutkan dengan faktor material, faktor metode, faktor alat, faktor keuangan, dan yang memberikan kontribusi pengaruh paling kecil adalah faktor lingkungan.

\section{DAFTAR PUSTAKA}

Ghozali, I. 2017. Model Persamaan Struktural Konsep dan Aplikasi dengan Program AMOS 24 Update Bayesian SEM. Semarang: Badan Penerbit Universitas Diponegoro.

Hariman, F., Hardiatmo, H.C., dan Triwiyono, A. 2007. Evaluasi dan Program Pemeliharaan Jembatan dengan Metode Bridge Management System (BMS): Studi Kasus Empat Jembatan Propinsi DI Yogyakarta. Forum Teknik Sipil, 17 (3): 581-593.

Kirschenman, M.D. 1987. Adequate Budget for Project Resource Management. Journal of Management in Engineering, 3 (4): 308-313.

Laksono, T.D. 2007. Produktivitas pada Proyek Konstruksi. Teodolita, 8 (2): 11-18.

Partogi, M., dan Mulyono, A.T. 2015. Kinerja Kontraktor dari Tinjauan Aspek-Aspek SIDLACOM. Kumpulan Makalah FSTPT-2015. (Online), (http://fstpt.unila.ac.id/ wpcontent/uploads/2015/08/T148.docx, diakses 01 Juli 2020).

Pusat Penelitian dan Pengembangan Jalan dan Jembatan (PUSJATAN). 2010. Pedoman Preservasi Jembatan. Bandung. 